Dossiê: Segurança pública e reforma das polícias na América Latina

ENCARTE DIGITAL

\title{
Legitimidade da polícia Segurança pública para além da dissuasão
}

\author{
Police legitimacy \\ Criminal policy beyond deterrence
}

\author{
André Zanetic* \\ Bruno Paes Manso** \\ Ariadne Lima Natal*** \\ Thiago Rodrigues Oliveira****
}

\begin{abstract}
Resumo: As políticas de segurança pública no Brasil vêm sendo dominadas pelo modelo da teoria da dissuasão, a partir da crença na eficácia de medidas como a intensificação do patrulhamento policial ostensivo, o aumento das redes de vigilância e controle e o crescimento das prisões em flagrante. No entanto, a literatura internacional tem mostrado como uma polícia que vise à obediência normativa é mais eficaz e menos custosa. Este trabalho busca discutir a relevância da teoria da legitimidade e da justeza procedimental para o debate atual das reformas da polícia no contexto brasileiro e apontar como as políticas públicas de segurança implementadas no país tem adotado estratégias baseadas no modelo dissuasório. Indicamos como essa agenda de pesquisa pode contribuir para a discussão a respeito das reformas das polícias no Brasil e na América Latina.
\end{abstract}

Palavras-chave: Legitimidade da polícia. Teoria da dissuasão. Justeza procedimental. Políticas públicas de segurança.

Abstract: Criminal policies in Brazil are premised by the deterrence theory model, which is based on measures such as heavy-handed policing, the growth of social

* Doutor em Ciência Política pela Universidade de São Paulo (USP, São Paulo, SP. Brasil) e pesquisador de pós-doutorado no Núcleo de Estudos da Violência da Universidade de São Paulo<andrezanetic@gmail.com>.

** Doutor em Ciência Política pela Universidade de São Paulo, jornalista e pesquisador de pósdoutorado no Núcleo de Estudos da Violência da Universidade de São Paulo <mansobruno@ yahoo.com.br>.

*** Mestre e doutoranda em Sociologia pela Universidade de São Paulo e pesquisadora do Núcleo de Estudos da Violência da Universidade de São Paulo < ariadnenatal@gmail.com>.

**** Mestre em Sociologia pela Universidade de São Paulo e pesquisador do Núcleo de Estudos da Violência da Universidade de São Paulo <thiago.rodrigues.oliveira@usp.br>. 
control and surveillance mechanisms, and the increasing number of arrests by police officers. International literature, however, have demonstrated how a police organization which targets normative instead of instrumental compliance is more effective and less expensive. This paper aims at discussing the theoretical relevance of legitimacy and procedural justice theory for the current debate on police reform in Brazil. It also aims at pointing how the lack of studies concerning the effects of criminal policies implemented in this country have allowed deterrence-based strategies to prosper despite the doubtful results on criminal behavior control. We indicate how this research agenda might contribute to the discussion on police reform in Brazil and in Latin America.

Keywords: Police legitimacy. Deterrence theory. Procedural justice. Criminal policies.

\section{Introdução}

Vinte e oito anos depois da promulgação da Constituição em 1988, ainda persistem lacunas na compreensão sobre os efeitos dos novos marcos legais do regime democrático nas instituições públicas e na sociedade. No caso das instituições policiais, da justiça criminal e das prisões em especial, a arquitetura institucional e as funções constitucionais mantiveram-se praticamente as mesmas, tendo como resultado manutenção de práticas institucionais e de culturas organizacionais ainda balizadas pela legitimidade da ação violenta e discricionária do Estado (Lima et al., 2015). Com o passar dos anos, este arcabouço legal e jurídico acabou se mostrando disfuncional, contribuindo para o país enfrentar um aparente paradoxo: ao mesmo tempo que a sensação de impunidade se mantém como uma das principais preocupações da população, o Brasil se tornou um dos países que mais prendem no mundo e com polícias que apresentam taxas de letalidade elevada em seu trabalho cotidiano. Este artigo busca discutir a proposta para uma nova agenda de pesquisa sobre reformas na polícia a partir do conceito de legitimidade.

Embora o conceito seja também importante para a discussão em áreas como justiça criminal, prisões e reformas institucionais no âmbito da segurança pública, nosso foco aqui se dá em torno das práticas policiais e da relação dos agentes públicos com os cidadãos.

A discussão sobre o fortalecimento da legitimidade das polícias busca dialogar com algumas questões clássicas das ciências sociais acerca da regulação das condutas humanas: por que as pessoas obedecem às leis e as autoridades? Em que medida a obediência à lei e às autoridades está baseada na coerção (receio de sofrer sanção) e em que medida se baseia na disposição da população em obedecer diante da percepção de que esta é a coisa certa a se fazer? Além de entrar no debate a respeito de conceitos relacionados ao fortalecimento da autoridade e à obediência numa sociedade democrática, os 
estudos sobre legitimidade têm centrado esforços na investigação das práticas cotidianas de autoridades das áreas da segurança e da Justiça (Tyler, 1990; 2004; Jackson et al., 2012a).

Esses trabalhos têm apontado para a conclusão de que a obediência às leis e às autoridades pode ser mais custosa e ineficaz quando baseada na coerção do que a obediência estabelecida por autoridades que são vistas como legítimas. Conforme esses estudos, feitos principalmente em cidades da Europa e nos Estados Unidos, a legitimidade das autoridades se fortalece quando os integrantes das polícias e da justiça estabelecem cotidianamente com a população procedimentos percebidos como justos e corretos, o que levaria ao aumento da disposição para obedecer e cooperar com esses agentes públicos.

Nesse sentido, o debate internacional pode permitir novos enfoques sobre a discussão das reformas nas polícias e nas políticas de segurança pública no Brasil, que, nos últimos anos, vem sendo dominada pela agenda dissuasória, a partir da crença na eficácia de medidas de intensificação do patrulhamento policial ostensivo, crescimento das prisões em flagrante e no endurecimento das penas. A teoria da legitimidade e da justeza procedimental para o debate atual das reformas da polícia e da segurança pública no Brasil é relevante porque ajuda a mostrar como as políticas públicas de segurança implementadas no país tem adotado estratégias generalistas, baseadas em medidas dissuasórias, apesar dos resultados duvidosos dessa abordagem no controle do comportamento criminal e no fortalecimento da disposição para obedecer e cooperar com as autoridades. É nesse sentido que o país atingiu um total de 622.202 presos em 2014, a quarta maior população carcerária do mundo, de acordo com o Departamento Penitenciário Nacional (Depen), e o montante de 59.627 homicídios no mesmo ano, de acordo com o Mapa da Violência de 2016 (Waiselfisz, 2016), mantendo o país como o que mais se mata no mundo em termos absolutos e entre os quinze mais violentos em taxas por 100 mil habitantes.

O artigo está dividido em quatro seções. Primeiramente, buscamos definir conceitualmente a teoria da dissuasão, indicando as implicações desse modelo para um sistema de justiça criminal, no geral, e uma organização policial, em particular, que tenha sua estratégia de ação focada apenas nessa lógica instrumental. Em seguida, apontamos algumas políticas de segurança pública e alguns aspectos das polícias no Brasil que exemplificam como o modo como se lida com segurança é calcado na teoria da dissuasão. A terceira seção define a teoria da legitimidade e da justeza procedimental, argumentando, a partir da literatura, como uma polícia que vise à obediência normativa é mais eficaz e 
menos custosa. Por fim, indicamos como a agenda de pesquisa nesse campo, já bastante comum em outros países, pode contribuir para a discussão a respeito das reformas das polícias no Brasil e na América Latina.

\section{Teoria da dissuasão}

Assegurar o respeito às leis é um dos principais objetivos de todo sistema de segurança e justiça. Nas sociedades em que as leis são obedecidas há mais estabilidade, previsibilidade e segurança, beneficiando tanto aqueles que exercem autoridade, quanto a sociedade como um todo. No entanto, o respeito à lei nunca é algo garantido, de maneira que um dos desafios de qualquer estado é aumentar a disposição de seus cidadãos a respeitar as leis. Dentre os caminhos possíveis para assegurar o respeito à lei, a teoria da dissuasão tem sido tradicionalmente a principal influência para as instituições de segurança e justiça ocidentais.

Os determinantes do comportamento criminal e os sentidos da punição são questões abordadas pelo pensamento social pelo menos desde o século 18 e, embora diversas perspectivas e abordagens para o controle do crime tenham sido sugeridas por acadêmicos, gestores e legisladores, o modelo da teoria da dissuasão se manteve constante com forte ascendência sobre as políticas e práticas adotadas pelas instituições de controle social.

Talvez os primeiros formuladores dessa perspectiva sejam Jeremy Bentham e Cesare Beccaria. Bentham, por exemplo, defendia que o crime advinha de considerações racionais e conscientes de cada indivíduo - uma pessoa, ao decidir pela execução do ato criminoso, avaliaria o custo benefício de sua ação e poderia decidir pela infração na possibilidade de os ganhos serem maiores do que os custos envolvidos (Kennedy, 1984). Essa abordagem utilitarista que coloca o indivíduo como um ator racional que decide por não cometer crimes devido aos riscos envolvidos foi levada ao extremo pelo economista Gary Becker (1968), que elaborou um modelo econométrico preditivo com uma função de utilidade que coloca, de um lado, incentivos positivos do comportamento criminal (como os bens subtraídos) e, de outro, incentivos negativos de dissuasão (a possibilidade de ser pego e a severidade da punição), buscando sua maximização.

A consequência direta dessa abordagem, sob a perspectiva da gestão pública, é um sistema de justiça criminal que faça com que os riscos para um potencial criminoso sejam altos a ponto de não compensarem possíveis ganhos da carreira infracional. Mecanismos de controle social, assim, buscam convencer indivíduos racionais que um ato criminal não vale o risco. A obediência às leis, portanto, seria assegurada pelo risco crível de sanções 
severas aos criminosos; trata-se de uma obediência instrumental (Jackson et al., 2012b).

A teoria da dissuasão, assim, prevê um policiamento ostensivo e punições duras - de modo que os indivíduos considerem uma alta probabilidade de serem capturados e sofram penas longas caso cometam algum crime (Kennedy, 1984). É esse o modelo tradicionalmente aplicado pelas políticas de segurança pública, ainda que uma série de pesquisas criminológicas apontem críticas a esse modelo - a certeza de sanção, por parte do indivíduo, não se mostra um preditor tão eficaz do cumprimento da lei como a legitimidade da autoridade (Tyler, 1990; 2004; Jackson et al., 2012a; Tankebe, 2013).

Um sistema de justiça criminal baseado no modelo dissuasório busca garantir a certeza e a rigidez das punições para desestimular possíveis criminosos, o que em geral envolve leis penais duras que prescrevam punições longas e severas mesmo para crimes de menor potencial ofensivo, um poder judiciário menos focado na garantia de direitos e mais voltado para o combate à impunidade, com promotores de justiça diligentes que entram com processos judiciais diante de quaisquer suspeitas de infrações, de modo a maximizar as chances de punição, e juízes que optam por aplicar penas duras.

Ainda que as leis e o sistema judicial devam ter características específicas para que se implemente o modelo da teoria da dissuasão, uma organização tem papel fundamental no efeito dissuasório dos mecanismos de controle social: a polícia. São os policiais, afinal, os responsáveis pelo aumento direto da percepção de riscos, uma vez que, em ronda urbana, fiscalizam o funcionamento cotidiano das cidades, sendo os primeiros acionados em caso de cometimento de crimes (seja por flagrante ou por chamado). Uma consequência direta, assim, da aplicação da teoria da dissuasão é uma polícia com características centrais de controle.

Dado que o objetivo principal desse modelo é garantir a certeza de uma sanção severa, uma característica fundamental do policiamento dissuasório é a intensa vigilância: se as pessoas suspeitarem que estão sendo vigiadas o tempo todo, elas estariam menos propensas cometer atos criminosos. Assim, esse modelo pressupõe políticas públicas que envolvem, por exemplo, um vultuoso efetivo policial patrulhando as ruas e situados em locais de grande visibilidade, promovendo a sensação de estarem em todos os lugares, além de contar com auxílio tecnológico do monitoramento por meio de câmeras de vigilância espalhadas por toda a cidade.

No intuito de aumentar a percepção de risco por parte da população, outra característica das polícias no modelo da teoria da dissuasão é o policiamento ostensivo. Policiais armados, com armas à vista, apontadas para fora de suas 
viaturas enquanto patrulham geram percepção a possíveis detratores do grande risco de serem pegos e dão dimensão da severidade com que serão tratados os autores de infrações penais capturados. No geral, o modelo dissuasório abre espaço para a emergência de uma polícia mais violenta, que age com maior truculência, de modo que sua própria ação consiste em uma ameaça dissuasória aos criminosos em potencial - uma vez que "os direitos dos infratores tendem a ser vistos como um empecilho a um controle efetivo da criminalidade" (Jackson et al., 2012b, p. 3, tradução nossa). ${ }^{1}$

Outra característica de um trabalho policial que se baseia no modelo dissuasório é a constante valorização de números e indicadores da "eficiência policial". Assim, a quantidade de apreensões feitas, de prisões realizadas, de abordagens feitas e de dinheiro investido seriam parâmetros que mensuram o quão eficaz tem sido a força policial. Políticas públicas que valorizem esses aspectos - em detrimento de questões como a percepção da população a respeito de medo e insegurança ou a qualidade do tratamento dos policiais, por exemplo - são exemplos de medidas essencialmente dissuasórias.

Resumidamente, a teoria da dissuasão prevê que as instituições de controle social, no geral, e a polícia, em particular, tratem os indivíduos como potenciais criminosos. Se quaisquer cidadãos podem, eventualmente, incorrer em atos criminosos, é dever dessas instituições dissuadi-los dessa decisão, ainda que motivados por razões instrumentais. E é particularmente nessa perspectiva, dentre outras, que a abordagem da legitimidade e da teoria da justeza procedimental se opõem ao modelo da dissuasão, conforme será explicado mais adiante: com maior qualidade no tratamento dos policiais à população, sem considerar cidadãos como potenciais criminosos, pode-se chegar a uma obediência não instrumental, mas normativa.

\section{Políticas de segurança pública}

Grande parte do repertório das estratégias de segurança pública que são propostas e implementadas no Brasil, particularmente, como soluções para problemas de segurança estão calcadas na teoria da dissuasão. Nosso modelo de policiamento tradicional se baseia em pressupostos instrumentais, se valendo da exacerbação de táticas repressivas como o policiamento ostensivo, as abordagens, as apreensões e as prisões, apresentadas como sinônimo da eficiência do trabalho policial e onipresentes tanto nas prestações de contas dos gestores policiais, quanto nos planos de metas direcionados às

\footnotetext{
${ }^{1}$ No original: "Offenders' right tend to be seen as a constraint on effective crime control" (Jackson et al., 2012b, p. 3).
} 
corporações. Muitas leis de caráter mais punitivo são aprovadas rapidamente em um contexto de forte demanda da opinião pública (Azevedo e Cifali, 2015, p. 118), indicando que mesmo as mudanças no campo da segurança pública normalmente apontam para uma reafirmação da lógica instrumental.

Um primeiro exemplo disso é a própria herança da estrutura militar das organizações responsáveis pelo policiamento ostensivo. Se, em cada unidade federativa, a respectiva polícia civil fica a cargo de todo o trabalho investigativo, a ronda urbana e a preservação da ordem pública são realizadas por polícias militares. Nesse sentido, em muitos aspectos, seguem a lógica das forças armadas de combate ao inimigo, de alto grau de disciplina e hierarquia interna, de autoidentificação como "militares", em contraposição aos "civis". Linhares de Albuquerque e Machado, analisando a Jornada de Instrução Militar (JIM) da polícia militar da Bahia, identificam como o próprio treinamento dos oficiais promove uma espécie de substituição da identidade civil pela identidade militar e elege o cidadão - criminoso em potencial, sempre suspeito - como o inimigo a ser combatido (Linhares de Albuquerque e Machado, 2001, p. 221).

Outro exemplo de como as políticas públicas de segurança estão calcadas nessa lógica instrumental é o Programa de Metas e de Bonificação Policial, do governo do estado de São Paulo. O programa, que tem como objetivo reduzir a incidência de roubos e furto de veículos, roubos em geral e crimes contra a vida, busca bonificar policiais militares caso as taxas criminais dessas infrações se mantenham em patamares especificados. "Isto estimula o trabalho em equipe. As metas são definidas anteriormente. Isto dá objetividade ao trabalho da polícia"2 - essa foi a declaração do governador Geraldo Alckmin a respeito do programa em 2014, evidenciando a importância dada aos números, tidos como indicadores da eficácia policial, conforme sugere a teoria da dissuasão (Ratton et al., 2011).

Sobre a relação entre gastos em segurança pública e "resultados", podemos observar que houve também crescimento nos gastos com segurança em todos os estados brasileiros, com destaque para os estados nordestinos estes estão entre aqueles que lideraram os aumentos. Para se ter uma ideia dos valores, segundo dados orçamentários, os gastos com segurança no Brasil cresceram em média $83 \%$ entre 2000 e 2009 no Brasil, descontando a inflação (Morais Filho et al., 2011). Em particular, os 642.244 membros das forças policiais brasileiras (entre policiais militares, policiais civis e guardas municipais) surpreendem quando o número é comparado com o efetivo de outros países (Lima et al., 2016).

\footnotetext{
${ }^{2}<$ www.saopaulo.sp.gov.br/spnoticias/lenoticia.php?id=235436\&c $=6>(23$ maio 2016).
} 
Conforme mencionado acima, o investimento em segurança pública e o aumento no do efetivo policial são tidos como uma medida de ampliação da eficácia, ainda que seu efeito isolado sobre a incidência de criminalidade não tenha sido de fato testado pela literatura. Conforme apontam Lima e colegas, "o país gasta o equivalente a países desenvolvidos e nem por isso consegue reverter o quadro de medo e insegurança, muito em função de um modelo falido de organização policial e administração de conflitos" (Lima et al., 2016, p. 54).

Para garantir certeza de punição, as estratégias de controle criminal têm se baseado menos em métodos de investigação e esclarecimento de delitos graves e mais no policiamento ostensivo, com intensificação de barreiras policiais e abordagens que têm como consequência o aumento expressivo do número de pessoas encarceradas. Dados de 2006 indicam que a Polícia Militar de São Paulo realizou cerca de 133 abordagens para efetuar uma prisão (Pinc, 2007), o que indica o grande volume de recursos humanos e materiais aplicados quando o controle do crime se baseia em métodos instrumentais. Entre 2005 e 2012, o total de presos cresceu em todas as 27 unidades da federação. O aumento médio da população carcerária foi da ordem de $74 \%$, chegando a 515.482 detentos, situação que já colocava o Brasil entre os quatro países que mais prendem no mundo (Lima et al., 2016).

Conforme prevê o modelo instrumental, a certeza de uma punição severa deve ter um efeito dissuasório sobre os indivíduos, que deixariam de cometer crimes. Nesse sentido, o aumento das taxas de encarceramento teria como efeito a diminuição das estatísticas criminais. Alguns estudos no Brasil buscaram testar essa hipótese - os resultados, no entanto, não permitem concluir a eficácia da teoria da dissuasão no combate à criminalidade.

É o que demonstram os trabalhos de Lourenço (2015) e Sachsida e Mendonça (2014) a respeito das estratégias de segurança pública no estado baiano, por exemplo. Lourenço, nesse estudo, buscou testar a hipótese da teoria da dissuasão com dados oficiais de segurança pública do estado entre 2005 e 2012. Resumidamente, seu objetivo foi investigar os efeitos de um policiamento mais ostensivo e do aumento das taxas de encarceramento de um ano sobre a incidência de crimes no ano seguinte, ou seja, testar se o aumento do número de presos de um ano fez com que houvesse menos crimes no outro. Lourenço encontrou, no entanto, efeitos significativos e positivos - ou seja, conforme aumenta o número de presos de um ano, aumenta também o número de crimes no ano seguinte. Isso demonstra, para esse caso particular, a ineficácia da teoria da dissuasão na contenção da criminalidade (Lourenço, 2015). 
Outro estudo cujo objeto empírico está circunscrito no caso brasileiro foi realizado por Nadanovsky (2009). O objetivo desse trabalho foi especificamente testar a hipótese da teoria da dissuasão, argumentando que o aumento das taxas de encarceramento do estado de São Paulo teria causado a queda nas taxas de homicídio do ano seguinte. No entanto, há uma série de críticas às conclusões desse trabalho. ${ }^{3}$

Desta forma, vê-se que os resultados dos estudos que buscaram testar a hipótese da teoria da dissuasão no Brasil são, no mínimo, inconclusivos. Ainda assim, trata-se da lógica aplicada pelas políticas de segurança pública e pelas polícias estaduais, especialmente as militares. Com o objetivo de convencer as pessoas a não cometer crimes por conta da certeza de punição severa, o policiamento ostensivo no Brasil tem sido violento, caro e ineficaz, raramente buscando avaliar a percepção dos cidadãos a respeito dessas instituições. Esse modelo de polícias calcado na teoria da dissuasão é especialmente criticado por autores como Tyler (1990; 2004) e Jackson et al. (2012a), que propõem uma lógica de atuação e de políticas públicas baseada em outra teoria: a da legitimidade e da justeza procedimental.

\section{Legitimidade e justeza procedimental}

Para compreendermos os fundamentos e o desenvolvimento das teorias relacionadas às dimensões da legitimidade e da justeza procedimental, especialmente no caso policial, e tecermos comparações com o cenário brasileiro, como pretendemos aqui, é importante de antemão situarmos a especificidade da organização das polícias brasileiras em relação aos modelos policiais existentes nos locais em que estas teorias têm sido estudadas. Diferentemente da maior parte dos países do mundo, no Brasil a força policial responsável pela parcela mais substantiva da execução do trabalho policial, que são as polícias estaduais, são organizadas de forma bipartida. Ou seja, uma parte do trabalho policial, constituído por suas funções investigativas e judiciárias, é desempenhada por uma corporação - a polícia civil - enquanto que a outra - a polícia militar, que é responsável pelo policiamento dito

\footnotetext{
${ }^{3}$ Para de fato testar o efeito do encarceramento sobre a diminuição de homicídios, a variável a ser utilizada como tratamento deveria ser o número de presos condenados por homicídio, do contrário há um viés de seleção no modelo (a não ser que o autor argumente que o aprisionamento relativo a qualquer crime tenha um efeito dissuasor sobre a intenção de cometimento de homicídio, o que não foi discutido); o modelo bivariado simples, proposto pelo autor, fere o princípio de exogeneidade das análises de regressão, isto é, há covariáveis importantes não incluídas, o que gera um viés de variáveis omitidas. Além disso, a correlação apontada é potencialmente espúria: o aumento no número de presos fortaleceu o Primeiro Comando da Capital, cuja atuação é tida como um dos fatores responsáveis pela queda dos homicídios (Dias, 2011).
} 
preventivo e ostensivo - é desempenhada por uma corporação distinta. Essa separação do trabalho policial em duas corporações é responsável por uma ampla gama de problemas institucionais que, tal como apontam muitos especialistas, dificultam sobremaneira uma execução mais eficiente e eficaz da realização adequada do policiamento. Há uma considerável literatura que tem lidado com essa problemática (Sapori, 2016; Souza e Battibugli, 2014; Lima et al., 2014; Azevedo, 2013; Teixeira, 2013; Sapori e Andrade, 2013; Junior et al., 2011; Zaluar, 2007; Muniz e Musumeci, 2000; Adorno, 1998), e há consenso que entre os principais problemas decorrentes dessa bipartição estão o corporativismo, a duplicação de esforços, as desconfianças e desavenças entre as forças, a perda de informação e falta de comunicação, que muitas vezes impedem a realização efetiva do trabalho policial, e os elevados custos relativos a necessidade de se despender recursos para a sustentação de duas organizações distintas.

Sem desconsiderar a importância do tema das reformas policiais brasileiras, no qual a divisão entre as polícias tem um papel de extrema importância, devemos aqui deixar claro que o tema da legitimidade - de sua construção, seus determinantes e seus impactos - é transversal à estrutura e à forma com que as instituições do sistema de justiça e segurança pública são organizadas. Ela diz respeito à forma como os agentes públicos interagem com os cidadãos, conquistam a sua confiança e, em conjunto com eles, criam uma relação em que esse agente pode ser compreendido e reconhecido como um representante mais adequado e apropriado para a realização das tarefas que lhe foram designadas desempenhar. $\mathrm{O}$ fortalecimento desse laço é que tem sido identificado como uma poderosa dimensão relativa ao exercício da autoridade de forma que esta seja mais eficaz do ponto de vista dos que exercem o poder e mais bem aceita e considerada justa por parte dos cidadãos. Portanto, trata-se de um eixo transversal que, embora também dependente das estruturas institucionais nas quais os poderes estão organizados, guarda certa autonomia com essas estruturas. É de se esperar que a implementação dos princípios da justeza procedimental tanto nas atuais polícias civis quanto militares (assim como nos demais órgãos do sistema de justiça criminal), independentemente de outras reformas que possam também trazer importantes avanços para a área, possam trazer bons resultados em relação à ordem das coisas através das quais as polícias atualmente se organizam e desenvolvem suas atividades.

Em contextos de sociedades democráticas, basear o sistema legal e o trabalho da polícia em monitoramento, vigilância e coerção, além de ser custoso, pois cria um sistema que demanda recursos e expansão constante, 
também pode ser controverso, pois este modelo envolve maior ênfase na intrusão, gera resistências e questionamento por parte da sociedade civil. $\mathrm{O}$ mandato policial tem limite tanto em termos de aplicação, quanto em termos de alcance. Embora as forças policiais tenham autorização para recorrer à coerção em determinadas situações, o uso deste recurso é limitado pelos controles legais e, principalmente, pelo consentimento social, que circunscrevem como e quando o poder de coerção pode ser utilizado. Em uma democracia a solução policial é sempre finita, pontual e provisória, de maneira que a ordem pública não pode se sustentar na coerção, pois ela não é uma solução em si, mas sim um recurso temporário (Muniz e Proença Jr., 2014).

Como vimos, embora os esforços do estado no sentido de garantir o cumprimento das leis e a ordem pública tenham se focado primordialmente no modelo dissuasório que envolve a ameaça ou uso de punição como estratégia de controle social, existem poucas pesquisas e resultados conclusivos a respeito do efeito deste modelo no contexto brasileiro. Em pesquisas realizadas sobretudo em países anglo-saxões, Tom Tyler tem explorado a hipótese de que o respeito às leis pode estar mais relacionado com o reconhecimento da autoridade como legítima do que com a coerção e o receio de ser punido (Tyler, 2004; Sunshine e Tyler, 2003). Isto não significa dizer que as práticas ligadas à teoria da dissuasão sejam ineficazes ou não cumpram o papel de estimular o respeito à lei, mas indica a necessidade de considerarmos que sua influência pode ser limitada, além de apontar a necessidade de verificarmos outros caminhos que estimulem respeito à lei e às instituições. Segundo Tyler (1990), a obediência às leis e às autoridades pode ser motivada por razões instrumentais ou por razões normativas. As razões instrumentais envolveriam um cálculo pragmático que leva em conta o risco e a severidade da punição, de maneira que a obediência se basearia mais na resignação e no medo do que no reconhecimento da autoridade. Para a polícia este seria um modelo menos eficiente de garantir a obediência às leis não só porque é mais economicamente custoso, mas também porque ele distancia a autoridade da sociedade e não motiva a sua participação e cooperação. Em contraposição, Tyler explora um modelo de regulação em que a obediência se daria por razões positivas, de maneira que a aquiescência seria uma forma de consentimento e comprometimento voluntário com as ações da autoridade (Bottoms e Tankebe, 2012).

A polícia precisa que as pessoas aceitem suas decisões e respeitem à lei não porque se sentem ameaçadas, mas porque escolhem fazê-lo. Ainda que seja prerrogativa da polícia fazer o uso da força para coagir indivíduos com objetivo de fazê-los respeitar as leis, concentrar todos os esforços das 
instituições policiais apenas no modelo dissuasor pode não ser o método de trabalho mais adequado, pois por mais eficaz que a polícia seja, é impossível que esteja em todos os lugares o tempo todo.

Deste modo, para além dos motivos instrumentais baseadas em sistemas de sanções e benefícios, faz-se necessário pensar a obediência às leis por motivação normativa. Quando podem contar que a maior parte da população vai respeitar as leis, então as autoridades irão minimizar os esforços e recursos alocados nos sistemas de monitoramento e controle, concentrando seus escassos recursos nos problemas considerados realmente graves. Este seria também um caminho com maiores chances de estabilidade ao longo do tempo, visto que o apoio público às autoridades e instituições não estaria condicionado ao seu desempenho ou demonstrações de força, sendo, portanto, menos afetados por circunstâncias ou situações de crise.

A legitimidade é vital para instituições e autoridades na medida em que ela justifica o exercício de poder. Embora as definições de legitimidade possam variar substancialmente, uma ideia central para vários autores é a de que legitimidade envolve o reconhecimento de uma autoridade e de seu direito a emitir comandos e o consequente dever de obedecer (Beetham, 1991; Coicaud, 2002; Bottoms e Tankebe, 2012). Segundo Beetham (1991), a legitimidade é constituída por três dimensões: consentimento (reconhecimento do direito da autoridade de exercer poder), legalidade (poderes prescritos de acordo com normas e valores sociais) e valores compartilhados (convergência entre objetivos e valores entre as autoridades e aqueles que a elas se submetem). Para se estabelecer, manter e se reproduzir, todas as instituições precisam se legitimar, de maneira que a legitimidade também é a base do poder da polícia. Uma força policial legítima seria aquela que é obedecida não por medo, mas porque exerce o poder de maneira adequada. De acordo com as dimensões propostas por Beetham, a legitimidade da polícia seria, portanto, a percepção de que a polícia age de acordo com certas regras, que são justas e justificáveis e que gera consentimento do público (Jackson e Bradford, 2010).

Segundo o modelo regulatório de legitimidade proposto por Tyler, o melhor caminho para garantir o respeito à lei e a cooperação com a polícia seria a internalização de valores que são percebidos pelos indivíduos como uma motivação própria e imperativa. As origens desta abordagem de legitimidade remontam a Weber (2004), segundo o qual a habilidade que uma autoridade tem para emitir comandos que serão obedecidos não se fundamentaria apenas na possessão do poder (obediência fundada na ameaça e na força), mas estaria relacionada à difusão de uma crença, por parte do público, de que 
essa autoridade deve ser obedecida em razão de características distintivas (os três tipos de dominação: carismática, tradicional ou legal) que garantiriam sua legitimidade.

Assim como Weber (2004), também Durkheim (1999), Freud (2011) e Elias (1997) tratam em alguma medida de processos de internalização de normas e valores sociais, inicialmente externas e até mesmo conflitantes com interesses e impulsos individuais, mas que eventualmente se tornam parte das motivações internas dos sujeitos e guiam suas escolhas e comportamentos sem depender constantemente de um sistema de vigilância, incentivos e sanções. No entanto, no modelo da legitimidade, a motivação para obedecer não está na coerção, no constrangimento social, na culpa ou nos valores morais, esta motivação está na percepção de que a autoridade é legítima. Esta distinção é importante, pois embora a moralidade e o entendimento do certo e errado sejam construções socialmente compartilhadas, em sociedades diversas e complexas nós lidamos com percepções que variam entre distintos grupos e contextos (Hitlin e Vaisey, 2013) o que aumenta o desafio para o exercício da autoridade e obtenção de cooperação e obediência. Desta forma, segundo o modelo proposto por Tyler, uma autoridade considerada legítima tem o poder de determinar o que são comportamentos apropriados e obtém consentimento e adesão a despeito da diversidade de posicionamentos, considerações morais e interesses pessoais (Tyler, 2003).

Para assegurar a legitimidade da autoridade, Tyler argumenta que um elemento fundamental é o julgamento que as pessoas fazem a respeito da forma como a polícia age na resolução de conflitos e como os policiais tratam as pessoas no cotidiano. Uma forma de aumentar as chances de apoio às decisões das autoridades, mesmo nas situações em que os resultados propostos são contrários às expectativas e interesses das partes, é demonstrar que estas decisões seguem o que Tyler chama de "justeza procedimental" (procedural justice, no original), um conceito que faz referência à qualidade do processo decisório e do tratamento interpessoal (Sunshine e Tyler, 2003; Tyler, 2004; Tyler, 2009). Segundo o autor, os julgamentos a respeito da forma como as instituições agem na tomada de decisões e no contato cotidiano com os cidadãos levam em conta a existência de: a) participação nas decisões, ou seja, se as pessoas envolvidas são ouvidas e seus pontos de vista considerados; b) neutralidade, que envolve decisões objetivas baseadas em fatos, sem viés pessoal, discriminação ou favorecimento de grupos específicos; c) transparência com relação aos procedimentos e decisões tomadas; d) qualidade do tratamento interpessoal, o que envolve, educação, dignidade, respeito e cortesia; e) confiança nas intenções das autoridades e que suas 
decisões levam em consideração o bem-estar e a necessidade daqueles que são afetados (Tyler, 2004).

A percepção de que as instituições agem com justeza procedimental cria envolvimento e estimula sentimentos de responsabilidade e leva à legitimação por meio de um senso de obrigação em obedecer, pois quando agem de maneira justa, fundamentam o direito de exercer o poder. A importância do tratamento digno e respeitoso para a qualidade da interação entre a polícia e a sociedade não é novidade, o que Tyler traz são pesquisas empíricas e evidências que mostram o impacto deste tipo de abordagem para a legitimidade da autoridade. As pesquisas de Tyler apontam que o efeito da justeza procedimental não se limitaria aos episódios de contato com a polícia, mas consistiria em longo prazo e afetaria tanto os próximos contatos com a polícia quanto a avaliação da instituição de maneira geral (Sunshine e Tyler, 2003; Tyler, 2004). Os estudos apontam ainda que a justeza procedimental está fortemente ligada à legitimidade e teria mais peso do que os julgamentos sobre eficiência da polícia, ou seja, a disposição em respeitar e cooperar com a polícia seria motivada mais pela forma como a polícia age do que a percepção de eficiência ou resultados favoráveis (Sunshine e Tyler, 2003; Hinds e Murphy, 2007; Jackson et al., 2012a; Wolfe et al., 2016).

A legitimidade deve ser a base do poder da polícia em uma sociedade democrática. Para que uma força policial seja considerada legítima, ela precisa demonstrar, por meio de sua atuação cotidiana, que exerce o poder de maneira adequada e que segue procedimentos justos - tal atuação justificaria a obediência voluntária do público. Quando as pessoas veem a polícia como legítima, aumentam as suas chances de cooperar com policiais, de respeitar suas determinações e de obedecer às leis, não em razão do medo ou em razão de valores individuais, mas por reconhecer e acreditar nas motivações de sua autoridade.

Estudos conduzidos nos Estados Unidos (Sunshine e Tyler, 2003; Wolfe et al., 2016), no Reino Unido (Jackson et al., 2012a; Bradford, 2016) e na Austrália (Hinds e Murphy, 2007), dentre outros, chegaram a esses resultados. A partir de desenhos de survey, as pesquisas buscaram mensurar a percepção pública a respeito da performance e do tratamento que recebem dos policiais, as atitudes e os valores em relação à obediência às autoridades, a anuência às regras e a percepção de risco de sanção em casos de desobediência. Por meio de modelos de regressão e de equações estruturais, ${ }^{4}$ verificaram como o efeito

\footnotetext{
${ }^{4}$ Modelagem de equações estruturais é uma técnica estatística que incorpora modelos de mensuração e modelos de regressão em um único modelo. Trata-se de uma análise de caminhos com variáveis latentes estimadas a partir de análises fatoriais confirmatórias.
} 
de legitimidade policial sobre a obediências às leis, a partir de incentivos positivos, é mais significativo do que o efeito da própria moralidade pessoal ou da certeza de punição, com base em incentivos negativos.

No entanto, em contextos em que a legitimidade é muito pequena ou ausente, haverá menos disposição em respeitar e obedecer voluntariamente às decisões da polícia, minando sua relação com a sociedade em razão de distanciamento, desconfiança, raiva e resistência. Quando o poder de polícia possui pouco respaldo e consentimento social, aumentam as resistências e as chances das relações entre polícia e sociedade se tornarem hostis, há recrudescimento, com maior risco de uso da força, que passa a ser usada com mais frequência e intensidade do que seria necessário em uma situação de proximidade, de maneira que a perda de legitimidade implica em riscos e custos (Muniz e Proença Jr., 2014).

Quando encontra resistências e desconfiança na execução de seu trabalho cotidiano, a polícia terá que mobilizar mais agentes, por mais tempo, prejudicando sua produtividade. A perda da credibilidade policial pode chegar ao ponto da polícia não ser mais chamada para intervir em situações em que sua presença seria esperada e necessária, o que envolve desde a subnotificação de eventos que deveriam ser do conhecimento da polícia, até mesmo a adesão a resoluções privadas de conflitos, o que pode gerar ações ilegais e violência (Muniz e Proença Jr., 2014), que por sua vez alimentarão um sistema no qual as autoridades precisarão utilizar cada vez mais ameaças de coerção e vigilância, por meio de políticas caras e de eficácia questionável.

Enquanto as soluções para o controle da criminalidade e situações de conflitos estiverem baseadas primordialmente na ameaça do recurso da força, haverá pouca disposição em respeitar e aceitar a autoridade policial como legítima e a obediência dos indivíduos será motivada pela coerção ou por seus valores pessoais e não pela legitimidade da autoridade.

O modelo auto regulatório baseado na justeza procedimental e na legitimidade é uma mudança na forma como se pensa a relação entre o público, as leis e as autoridades, incluindo a polícia, pois a legitimidade seria resultado do uso de procedimentos justos tanto na elaboração e na implementação de leis e políticas públicas, quanto na prática cotidiana dos seus agentes que exercem a autoridade no contato direto com os cidadãos. $\mathrm{O}$ objetivo final deste modelo vai além de simplesmente garantir a obediência (que pode ser motivada por valores pessoais, razões instrumentais ou por medo) e visa uma disposição voluntária e normativa em obedecer às leis e às decisões das autoridades em longo prazo (motivada por respeito e reconhecimento da legitimidade). O modelo da legitimidade é desejável, 
assim, pois garante estabilidade e forma as bases necessárias para o bom funcionamento do estado de direito.

\section{Justeza procedimental na ação policial: aplicações práticas e agenda de pesquisas}

Ao questionarem a eficácia das estratégias de controle do crime alicerçadas centralmente nas práticas de coerção e punição, os trabalhos desenvolvidos no âmbito da justeza procedimental proporcionaram como consequência a construção de novas abordagens de referência para as ações institucionais desenvolvidas pelas polícias, e a intenção em transformar esse conhecimento em atividades práticas e de impacto no campo policial. Os resultados robustos dos estudos empíricos realizados nos diversos contextos mencionados ajudaram a apontar caminhos para o aprimoramento de políticas públicas policiais, com o foco na construção de uma melhor relação entre os agentes institucionais e as comunidades, com desdobramentos também nas ações voltadas ao controle das ofensas criminais e seu tratamento pelos agentes do sistema de justiça e segurança.

Muitos dos projetos desenvolvidos no âmbito dessa abordagem, situando apenas os mais recentes, realizam uma tradução dos princípios teóricos arquitetados pelos principais pesquisadores da área, transpondo tais princípios e ideias para uma linguagem acessível para o universo dos policiais e construindo perspectivas práticas de ação, muitas vezes em conjunto com universidades e centros especializados de estudo e construção de conhecimento sobre o tema. São os casos, por exemplo, da publicação Procedural justice for law enforcement: an overview (Kunard e Moe, 2015), elaborada para o departamento de justiça norte-americano com o objetivo de introduzir: princípios da justeza procedimental para policiais; o treinamento relacionado à construção da legitimidade policial elaborado pela polícia de Chicago e replicado por outras corporações norte-americanas (Reynolds, 2015); e ainda o programa de treinamento a respeito de estratégias de comunicação aplicado na Grande Manchester (Wheller et al., 2013).

A base desses diferentes projetos, de uma forma geral, se fundamenta no desenvolvimento e ensinamento dos principais conceitos relativos às teorias da justeza procedimental e da legitimidade policial, a partir da valorização da justiça e da lisura no tratamento, do respeito, da importância em dar voz aos cidadãos, fazendo-os sentir-se realmente acolhidos e representados, do desenvolvimento da transparência em todas as ações, assim como da imparcialidade e neutralidade na tomada de decisões. Outros pontos importantes são também trabalhados, como a relação entre justeza procedimental e uso da 
força e a ação focalizada em hot spots ${ }^{5}$ (Kunard e Moe, 2015, p. 5), e também as diferenças fundamentais entre atendimento justo e resultados esperados (cujas relações são muitas vezes nebulosas), valorizando a importância do tratamento e do processo no qual as decisões são feitas. Esses conceitos e estratégias são organizados para formar uma metodologia específica de formação focalizada nos princípios da justeza procedimental e sua aplicação prática, envolvendo para tanto a participação de especialistas renomados na área.

Ainda que existam fartas evidências da influência dos aspectos relacionados à justeza procedimental com a propensão à obediência às leis $\mathrm{e}$ à cooperação com a polícia, não são totalmente claros que tipos de práticas de intervenção podem de fato aprimorar a percepção das comunidades sobre o tratamento que recebem das forças policiais. Tendo em vista essas lacunas, muitos desses projetos que têm sido colocados em prática nessa linha tem como parte importante de seus objetivos a avaliação dessas perspectivas de intervenção com relação a seus impactos. Trata-se de uma agenda aberta, mas que tem ajudado a trazer respostas sobre essas questões.

O projeto desenvolvido na Grande Manchester, por exemplo, pode ser citado como uma dessas práticas de intervenção testadas empiricamente. $\mathrm{O}$ projeto teve como objetivo testar o impacto de um treinamento aplicado a um conjunto de policiais da região para aprimorar a qualidade das interações entre vítimas de crimes e policiais, focando no aperfeiçoamento das habilidades de comunicação prática dos agentes que realizaram o curso. Para a realização do teste empírico, foram selecionados randomicamente 339 policiais que passaram pelo treinamento para responder a um formulário on-line acerca de suas atitudes e comportamentos com relação às vítimas. Foram também selecionados outros 237 policiais que não passaram pelo treinamento, como grupo de controle. Os resultados indicaram que a intervenção realizada surtiu efeito em pontos importantes em que havia expectativas de impacto no que dizia respeito ao comportamento policial: em relação ao grupo de controle, os policiais que participaram da intervenção ampliaram positivamente sua visão sobre a importância de realizar um atendimento de qualidade; reconheceram a importância de ampliar a empatia; reconheceram a importância de inspirar confiança na relação com as vítimas; e reportaram tomar decisões em conjunto com os indivíduos atendidos. No que tange à percepção das vítimas de crimes atendidas pelos policiais que participaram da intervenção, estas também reportaram uma maior qualidade de tratamento por parte dos policiais em diferentes aspectos (Wheller et al., 2013). As principais referências teóricas

\footnotetext{
${ }^{5}$ Hot spots dizem respeito a áreas em um mapa com alta incidência de crimes.
} 
do projeto provêm de autores como Jackson et al. (2012a), Myhill e Quinton (2010) e Tyler (1990).

Para além dos contornos que adquiriu no cenário internacional e dos projetos que vêm sendo colocados em prática, o que essa literatura permite pensar sobre as forças policiais brasileiras? Em primeiro lugar, entre os (não muitos) estudos que já foram realizados sobre justeza procedimental e legitimidade policial fora dos cenários norte-americano e do Reino Unido, alguns achados mostram que o impacto dos fatores relacionados à justeza procedimental pode, em contextos diferentes, ocorrer de forma significativamente diversa da identificada naqueles cenários. Um estudo realizado por Tankebe (2009) em Gana, por exemplo, apresentou uma correlação muito mais forte da percepção de efetividade policial como determinante da legitimidade do que em contextos como Londres e Nova Iorque, ainda que a justeza procedimental seja também de grande relevância. Ainda que a aplicação dessas teorias que, no âmbito da atividade policial, preconizem a construção de uma melhor relação da polícia com o público tenha sido incipiente no cenário brasileiro até aqui, é possível apontar ao menos algumas tentativas que foram postas em prática com esse perfil. A principal delas relaciona-se à implantação de estratégias de policiamento comunitário, que é, sem dúvida, em termos de polícia, o estilo de ação mais próximo da ideia de legitimidade policial, ao buscar a construção da legitimidade da autoridade policial através de sua interação com a população no desenvolvimento de seu trabalho. A filosofia de policiamento comunitário enfatiza a aproximação entre polícia a comunidade e destaca a importância de um trabalho em conjunto em parceria com a sociedade, estimulando a cooperação para tornar as comunidades mais seguras, reduzir medo, prevenir crimes e melhorar a qualidade de vida. No entanto, esta cooperação é uma adesão voluntária, população não pode ser coagida a fazê-lo, mas pode ser estimulada se existir uma relação de confiança entre as partes.

Vale dizer, nesse sentido, que alguns estudos sobre experiências realizadas no Brasil têm apontado a existência de uma relação positiva da polícia comunitária com sensação de segurança e confiança em diferentes contextos nacionais em que o modelo foi implementado. Uma das primeiras experiências de implementação do modelo de polícia comunitária no país, realizada na cidade de São Paulo entre os anos de 1997 e 2001, foi avaliada de forma sistemática através de um estudo de survey. A pesquisa, que foi realizada com a população em 46 bairros (sendo que apenas 23 receberam o novo programa de policiamento, ficando os outros 23 como áreas de controle), mostrou uma sensível melhora na diminuição do medo e na imagem das polícias nos locais em que há policiamento comunitário e que a população 
sabe de sua existência (Kahn, 2002). Também foram realizadas, em outras localidades, processos de avaliação através de estudos qualitativos como grupos focais e entrevistas em profundidade com os cidadãos e também com policiais. Algumas das referências e análises presentes nesses estudos sobre a implementação do policiamento comunitário e seus resultados podem ser encontradas em Batitucci (2016), Godinho (2013), Beato (2006), Oliveira (2002) e Núcleo de Estudos da Violência (2003a; 2003b; 2009).

Mas esses estudos têm apontado, também, alguns dos muitos fatores pelos quais a polícia comunitária tem encontrado dificuldades para se tornar uma estratégia de fato apoiada e implementada. Entre eles, o fato de que parte considerável dos policiais não incorpora as prerrogativas desse tipo de policiamento, o que pode estar relacionado à falta de formação adequada e também ao fato de haver muitas resistências sobre esse tipo de policiamento no ambiente corporativo (Batitucci, 2016; Godinho, 2013), entre as quais, por exemplo, o fato de ser considerado mais light e menos eficaz por muitos policiais (Kahn, 2002).

Dado o impacto que as práticas relacionadas à justeza procedimental e ao fortalecimento da legitimidade tem para a sociedade e para a própria organização e, ao mesmo tempo, dada a pouca ênfase concedida a essas correntes teóricas e ao tipo de estratégias por ela proporcionadas, faz-se necessária a construção de uma agenda de pesquisas voltada à produção de conhecimentos sobre esses fatores no cenário nacional, levando em conta sua ampla diversidade e diferentes características em relação ao cenário internacional. Devem ser destacados, nesse sentido, aspectos de grande influência sobre a construção da legitimidade dos agentes policiais que são comuns à nossa realidade, como as questões relativas às práticas de violência $\mathrm{e}$ má-conduta policial e os altos níveis de descrença e desconfiança da população sobre as instituições policiais.

Assim, uma agenda de pesquisas profícua para ser levada a cabo no cenário nacional deve levar em consideração tanto a aplicação dos estudos que já têm sido realizados no cenário internacional, considerando seus enormes avanços, quanto o estabelecimento de uma leitura crítica desses modelos existentes, considerando tanto as suas limitações quanto, e fundamentalmente, as características do cenário nacional, construídas através de suas diferenças culturais e sociais, bem como através de sua história.

\section{Conclusão}

Como têm mostrado pesquisas desenvolvidas no cenário internacional, a teoria da legitimidade e da justeza procedimental se constitui como uma 
concepção muito promissora no que diz respeito a aprimorar as relações entre a população e os agentes públicos de segurança, em especial os policiais. Essa concepção tem como seus principais potenciais a capacidade de possibilitar a construção de uma obediência normativa dos cidadãos com relação às leis e as autoridades, estreitando seus vínculos e reduzindo os custos da ação estatal e seus efeitos nocivos. Ainda não difundida no Brasil, a teoria da legitimidade e da justeza procedimental tem um vasto campo para ser difundida tanto enquanto pesquisa quanto enquanto prática de intervenção. A contribuição dessa teoria à reforma das polícias se relaciona sobretudo aos aspectos que caracterizam os contornos da cultura policial no país, e às possibilidades de transformação dos comportamentos desses agentes em suas relações com os cidadãos. Concluímos este artigo descrevendo abaixo algumas perspectivas para pesquisa, intervenção e possíveis desdobramentos para o campo.

A legitimidade das políticas de segurança e da ação policial se fortalece na medida em que estão voltadas a resolver questões cotidianas ligadas a determinadas vizinhanças e praticadas de forma eficaz e justa, sem exacerbar no uso da força, quando este se faz necessário, e evitando estratégias generalistas de aprisionamento. Nesse sentido, o aumento da legitimidade e da justeza procedimental passariam por políticas de segurança mais adequadas. A partir de análise de 43 revisões e 1.400 estudos, Abt e Winship (2016) apontam os elementos de eficiência mais impactantes no controle do crime, em especial o homicídio. Eles apontam a importância em manter o foco específico naqueles sob riscos mais fortes de sofrerem violência; esforço proativo de prevenção de violência antes que ocorra; aumento da percepção e legitimidade das estratégias e instituições; atenção cuidadosa à implementação do programa e à fidelidade; bem definida e compreendida teoria de mudança; engajamento ativo e parceria com as lideranças que importam.

A discussão sobre as medidas dissuasórias acaba tendo resultados no momento em que estão focadas na reversão de problemas diretamente percebidos e apontados como reais para a população local. Projetos com metas definidas e compreendidas pela população produzem aumento no engajamento ativo e a parceria desejada pelas autoridades. Assim, argumentamos que uma polícia que atue seguindo o modelo da teoria da dissuasão atinge, no máximo, uma obediência às leis motivada por razões instrumentais - ao passo que uma polícia que tenha adquirido legitimidade a partir da qualidade de seu tratamento tende a gerar uma obediência normativa por parte da população, com os múltiplos benefícios que esse tipo de orientação para o comportamento tem sobre a efetiva obediência às leis. 
As pesquisas relacionadas a essa área devem, portanto, ser abrangentes com relação a ação dos agentes públicos de segurança em suas relações com a população. A justeza procedimental tem de estar presente nas mais diferentes situações, que contemplem diferentes níveis de risco tanto para os agentes de segurança, quanto para aqueles que transgridam as leis e para a população local envolvida. Agir com justeza procedimental pode significar, entre outros exemplos possíveis, adequar e calibrar o uso da força policial à necessidade, à utilidade e às expectativas esperadas de acordo com cada ação. Não se deve perseguir agressores e utilizar armas de fogo em situações que irão gerar riscos desproporcionais para os indivíduos envolvidos em uma ocorrência, da mesma forma que não se deve tomar decisões em relação à segurança que afetem a vida da população de um bairro sem que esta possa compreender as razões e participar da discussão acerca de tais medidas. Ambos os tipos de situação, que podem ter níveis de risco amplamente diferenciados, são ações que podem ser percebidas como justas, adequadas e serem assimiladas pela população, ampliando a legitimidade dos agentes públicos com elas envolvidos.

Da mesma forma, agir com justeza procedimental também significa tratar igualmente os diversos grupos sociais, respeitando suas diferenças étnicas, culturais, de gênero, etc. Pesquisas e projetos que enfoquem a ação institucional frente às diferenças, em especial envolvendo segmentos das polícias com histórico de envolvimento e propensão a incorrer em tratamentos discriminatórios, desiguais e violentos, são fundamentais para a redução do preconceito e o aprimoramento das relações das instituições com as diferentes comunidades e seus habitantes.

Essa agenda de pesquisas deve contemplar uma ampla gama de linhas, levando em conta programas que abordem temas como a questão da justeza procedimental nas prisões e seus impactos para a relação dos presos entre si, com os agentes e com as perspectivas de progressão de suas penas e reinserção social; o impacto da justeza procedimental sobre homicídios e outros crimes graves; a questão da justiça restaurativa, capaz de modificar a atuação institucional da justiça propondo ações com participação direta do ofensor, da vítima e da comunidade no processo de reparação de danos, paulatinamente ampliando a legitimidade da justiça e seus agentes. Da mesma forma, são também de grande importância o desenvolvimento de pesquisas e desenhos de intervenção focados na autoconstrução da legitimidade (selflegitimacy) dos agentes de justiça e segurança, que diz respeito aos processos e atores responsáveis pela construção da confiança desses agentes em sua própria legitimidade. Diferentes pesquisas têm mostrado uma importante relação entre a auto-legitimidade dos policiais e a justeza procedimental, e 
consequentemente com uma ampliação da própria legitimidade dos policiais frente à população (Bradford e Quinton, 2014). O debate sobre legitimidade permite ampliar as possibilidades na discussão sobre reformas que parece estancada nas armadilhas imposta pela agenda dissuasória. A discussão sobre legitimidade permite ir além da dissuasão, oferecendo caminhos alternativos a um debate que parece estagnado e esgotado.

\section{Referências}

ABT, Thomas; WINSHIP, Chistopher. What works in reducing community violence: a meta-review and field study for the northern triangle. United States Agency for International Development, Washington, DC, 2016.

ADORNO, Sérgio. Consolidação democrática e políticas de segurança pública no Brasil: rupturas e continuidades. In: Jorge Zaverucha (org.). Democracia e instituições políticas Brasileiras no final do século XX. Recife: Bagaço, 1998.

AZEVEDO, Rodrigo Ghiringheli de. Elementos para modernização das polícias do Brasil. Revista Brasileira de Segurança Pública, v. 10, p. 8-20, 2016.

AZEVEDO, Rodrigo Ghiringhelli; CIFALI, Ana Cláudia. Política criminal e encarceramento no Brasil nos governos Lula e Dilma: elementos para um balanço de uma experiência de governo pós-neoliberal. Civitas, v. 15, n. 1, p. 105-127, 2015 $<10.15448 / 1984-7289.2015 .1 .19940>$.

BATITUCCI, Eduardo Cerqueira; GODINHO, Leticia; CASTRO, Luania Ludmilla; GOMES; Larissa Peixoto Vale. Policiamento comunitário e participação em Minas Gerais: entre a narrativa oficial e a efetividade das reformas. In: Almir de Oliveira Junior (org.). Instituições participativas no âmbito da segurança pública: programas impulsionados por instituições policiais. Rio de Janeiro: Ipea, 2016.

BEATO, Cláudio. Avaliação do policiamento comunitário da polícia militar de Minas Gerais em Belo Horizonte. Belo Horizonte: Crisp-UFMG, 2006. Relatório de pesquisa.

BECKER, Gary. Crime and punishment: an economic approach. Journal of Political Economy, v. 76, n. 2, p. 169-217, 1968.

BEETHAM, David. The legitimation of power. London: Macmillan, 1991.

BOTTOMS, Anthony; TANKEBE, Justice. Beyond procedural justice: a dialogic approach to legitimacy in criminal justice. The Journal Of Criminal Law and Criminology, v. 102, n. 1, p. 119-170, 2012.

BRADFORD, Ben; QUINTON, Paul. Self-legitimacy, police culture and support for democratic policing in an English constabulary. British Journal of Criminology, v. 54, n. 6, p. 1023-1046, 2014.

BRADFORD, Ben. Policing and social identity: procedural justice, inclusion and cooperation between police and public. Policing and Society, v. 24, n. 1, p. 22-43, $2012<10.1080 / 10439463.2012 .724068>$.

COICAUD, Jean-Marc. Legitimacy and politics: a contribution to the study of political right and political responsibility. Cambridege: Cambridge University Press, 2002. 
DIAS, Camila Nunes. Da pulverização ao monopólio da violência: expansão e consolidação do Primeiro Comando da Capital (PCC) no sistema carcerário paulista. São Paulo, 2011. Tese doutorado em Sociologia, Faculdade de Filosofia, Letras e Ciências Humanas, Universidade de São Paulo.

DURKHEIM, Emile. As regras do método sociológico. São Paulo: Martins Fontes, 1999.

ELIAS, Norbert. O processo civilizador. Uma história dos costumes. v. 1. Rio de Janeiro: Jorge Zahar, 1997.

FREUD, Sigmund. O mal-estar na civilização. São Paulo: Penguin Classics Companhia das Letras, 2011.

GODINHO, Letícia. Avanços e retrocessos na agenda da reforma comunitária do policiamento: balanço das experiências recentes. In: Guaracy Mingardi (org.). Violência e segurança pública. São Paulo: Editora Fundação Perseu Abramo, 2013.

HITLIN, Steven; VAISEY, Stephen. The new sociology of morality. Annual Review of Sociology, v. 39, p. 51-68, $2013<10.1146 /$ annurev-soc-071312-145628>.

HINDS, Lyn; MURPHY, Kristina. Public satisfaction with police: using procedural justice to improve police legitimacy. Australian \& New Zealand Journal of Criminology, v. 40, n. 1, p. 27-42, 2007.

JACKSON, Jonathan; BRADFORD, Ben. Police legitimacy: a conceptual review <ssrn.com/abstract $=1684507>$ (29 set. 2010).

JACKSON, Jonathan et al. Why do people comply with the law? Legitimacy and the influence of legal institutions. British Journal of Criminology, v. 52, n. 6, p. 1051-1071, 2012a.

JACKSON, Jonathan; KUHA, Jouni; BRADFORD, Ben; HOHL, Katrin; HOUGH, Mike. Policing by consent: understanding the dynamics of police power and legitimacy. ESS country specific topline results series, 1. European Commission, 2012b <https:// ssrn.com/abstract $=2168702>(7$ dez. 2016).

JUNIOR, Aldo Antonio dos Santos; FORMEHL, Kelly Cristina; PICCOLI, Daniela Lain. O ciclo completo de polícia no Brasil. Revista de Antropología Experimental, n. 11, p. 1-10, 2011.

KAHN, Tulio. Polícia Comunitária: pesquisa de avaliação da experiência no município de São Paulo. Revista do Ilanud, n. 19, 2002.

KENNEDY, Kelvin C. A critical appraisal of criminal deterrence theory. 88 Dick L. Rev, n. 1, p. 1-13, 1984 <http://digitalcommons.law.msu.edu/facpubs/42/> (7 dez. 2016).

KUNARD, Laura; MOE, Charlene. Procedural justice for law enforcement: an overview. Washington: Office of Community Oriented Policing Services, 2015.

LIMA, Renato Sérgio de; BUENO, Samira; SANTOS, Thandara. Opinião dos policiais brasileiros sobre reformas e modernização da segurança pública. São Paulo: Centro de Pesquisas Jurídicas Aplicadas, Escola de Direito, FGV, Fórum Brasileiro de Segurança Pública, 2014. 
LIMA, Renato Sérgio de; SINHORETTO, Jacqueline; BUENO, Samira. A gestão da vida e da segurança pública no Brasil. Sociedade e Estado, v. 30, n. 1, p. 123-144, $2015<10.1590 /$ S0102-69922015000100008>.

LIMA, Renato Sergio; BUENO, Samira; MINGARDI, Guaracy. Estado, polícias e segurança pública no Brasil. Revista Direito GV, v. 12, n. 1, p. 49-85, 2016 $<10.1590 / 2317-6172201603>$.

LINHARES DE ALBUQUERQUE, Carlos; MACHADO, Eduardo Paes. Sob o signo de Marte: modernização, ensino e ritos da instituição policial militar. Sociologias, v. 3, n. 5, p. 214-237, 2001.

LOURENÇO, Luiz Claudio. Prisão e dinâmicas de criminalidade: notas e possíveis efeitos das estratégias de Segurança Pública na Bahia (2005-2012). O Público e o Privado, n. 26, p. 53-67, 2015.

MYHILL, A; QUINTON, P. It 's a fair cop? Police legitimacy, public cooperation, and crime reduction. London: National Policing Improvement Agency, 2010.

MORAIS FILHO, Osvaldo Martins de; CARIO, Rebeca Dias; NOGUEIRA, Ronaldo Alves. Análise dos investimentos em Segurança Pública no Brasil entre 2000 e 2009. Revista Brasileira de Segurança Pública, v. 5, n. 1, p. 38-59, 2011.

MUNIZ, Jacqueline; PROENÇA JR, Domício. Mandato policial. In: Renato Sergio Lima; José Luiz Ratton; Rodrigo Ghiringhelli Azevedo (orgs.). Crime, polícia e justiça no Brasil. São Paulo: Contexto, 2014. p. 491-502.

MUNIZ, Jaqueline; MUSUMECI, Leonarda. As instituições de segurança pública do Estado do Rio de Janeiro. In: Carlos Lessa (org.). Reforma do estado e proteção social: os setores de saúde e segurança públicas no Rio de Janeiro. Rio de Janeiro: Editora UFRJ, 2000.

NADANOVSKY, Paulo. O aumento no encarceramento e a redução nos homicídios em São Paulo, Brasil, entre 1996 e 2005. Caderno de Saúde Pública, v. 25, n. 8, p. 1859-1864, $2009<10.1590 / \mathrm{S} 0102-311$ X2009000800022>.

NÚCLEO de Estudos da Violência. Manual de policiamento comunitário: polícia e comunidade na construção da segurança. São Paulo: NEV-USP, 2009.

NÚCLEO de Estudos da Violência. Polícias civil e militar: o policiamento que a sociedade deseja. São Paulo: NEV-USP, 2003a. Relatório final.

NÚCLEO de Estudos da Violência. Sociedade civil: o policiamento que a sociedade deseja. São Paulo: NEV-USP, 2003b. Relatório final.

OLIVEIRA, Nilson Vieira (org.). Policiamento comunitário: experiências no Brasil 2000- 2002. São Paulo: Página Viva, 2002.

PINC, Tania. Abordagem policial: um encontro (des) concertante entre a polícia e o público. Revista Brasileira de Segurança Pública, v. 1, n. 2, p. 6-23, 2007.

RATTON, José Luiz; TORRES, Valéria; BASTOS, Camila. Inquérito policial, Sistema de justiça criminal e políticas públicas de segurança: dilemas e limites da governança. Revista Sociedade e Estado, v. 26, n. 1, p. 29-58, $2011<10.1590 /$ S010269922011000100003>. 
REYNOLDS, Julia. (org.). Procedural justice and police legitimacy: using training as a foundation for strengthening community-police relationships. California Partnership for Safe Communities, 2015. Working draft.

SACHSIDA, Adolfo; MENDONÇA, Mario Jorge Cardoso de. Combatendo homicídios no Brasil: o que funciona em São Paulo funciona na Bahia? Brasília: Ipea, n. 1979, 2014. Texto para discussão.

SUNSHINE, Jason; TYLER, Tom R. The role of procedural justice and legitimacy in shaping public support for policing. Law and Society Review, v. 37, n. 3, p. 513-548, $2003<10.1111 / 1540-5893.3703$ aut $>$.

SAPORI, Luis Flávio. Como implantar o ciclo completo de polícia no Brasil? Revista Brasileira de Segurança Pública, v. 10, suplemento especial, p.50-58, 2016.

SAPORI, Luis Flávio; ANDRADE, Scheilla C. Desafios da governança do sistema policial no Brasil: o caso da política de integração das polícias em Minas Gerais. Revista Brasileira de Segurança Pública, v. 7, n. 1, 102-130, 2013.

SOUZA, Luís Antonio Francisco de; BATTIBUGLI, Thaís. O difícil caminho da reforma: a polícia e os limites do processo de reforma pós-redemocratização. Dilemas: Revista de Estudos de Conflito e Controle Social, v. 7, n. 2, p. 293-319, $2014<$ http:// hdl.handle.net/11449/115193> (7 dez. 2016).

TANKEBE, Justice. Public cooperation with the police in Ghana: does procedural fairness matter? Criminology, v. 47, n. 4, p. 1265-1293, $2009<10.1111 /$ j. 1745-9125. 2009.00175.x>.

TANKEBE, Justice. Viewing things differently: the dimensions of public perceptions of legitimacy. Criminology, v. 51, n. 1, p. 103-135, $2013<10.1111 /$ j.1745-9125. 2012.00291.x>.

TEIXEIRA, Nilo. A política de integração de Minas Gerais: A 'dependência de trajetória' na consolidação da política brasileira de segurança pública. Dilemas: Revista de Estudos de Conflito e Controle Social, v. 6, n. 3, p. 369-410, 2013.

TYLER, Tom R. Why people obey the law: procedural justice, legitimacy, and compliance. New Haven, CT: Yale University Press, 1990.

TYLER, Tom R. Procedural justice, legitimacy, and the effective rule of law. Crime and justice, v. 30, p. 283-357, 2003.

TYLER, Tom R. Enhancing police legitimacy. The annals of the American academy of political and social science, v. 593, n. 1, p. 84-99, $2004<10.1177 / 0002716203262627>$.

TYLER, Tom R. Legitimacy and criminal justice: the benefits of self-regulation. Ohio State Journal of Criminal Law, v. 7, n. 1, p. 307-359, 2009.

WAISELFISZ, Julio Jacobo. Mapa da violência 2016: homicídios por arma de fogo no Brasil. Brasília: Flacso Brasil, 2016.

WEBER, Max. Economia e sociedade: fundamentos da sociologia compreensiva. v. 2. São Paulo: Editora UnB, 2004. 
WHELlER, Levin; QUINTON, Paul; FILDES, Alistair; MILLS, Andy. The Greater Manchester police procedural justice training experiment: the impact of communication skills training on officers and victims of crime. College of Policing, 2013.

WOLFE, Scott; NIX, Justin; KAMINSKI, Robert; ROJEK, Jeff. Is the effect of procedural justice on police legitimacy invariant? Testing the generality of procedural justice and competing antecedents of legitimacy. Journal of Quantitative Criminology, v. 32, n. 2, p. 253-282, $2016<10.1007 /$ s10940-015-9263-8>.

ZALUAR, Alba. Democratização inacabada: Fracasso da segurança pública. Estudos Avançados, v. 21, n. 61, p. 31-49, $2007<10.1590 /$ S0103-40142007000300003>.

Autor correspondente:

André Zanetic

Av. Prof. Almeida Prado, 520 - Butantã

05508-900 São Paulo, SP, Brasil

Recebido em: 31 maio 2016.

Aprovado em: 7 nov. 2016. 